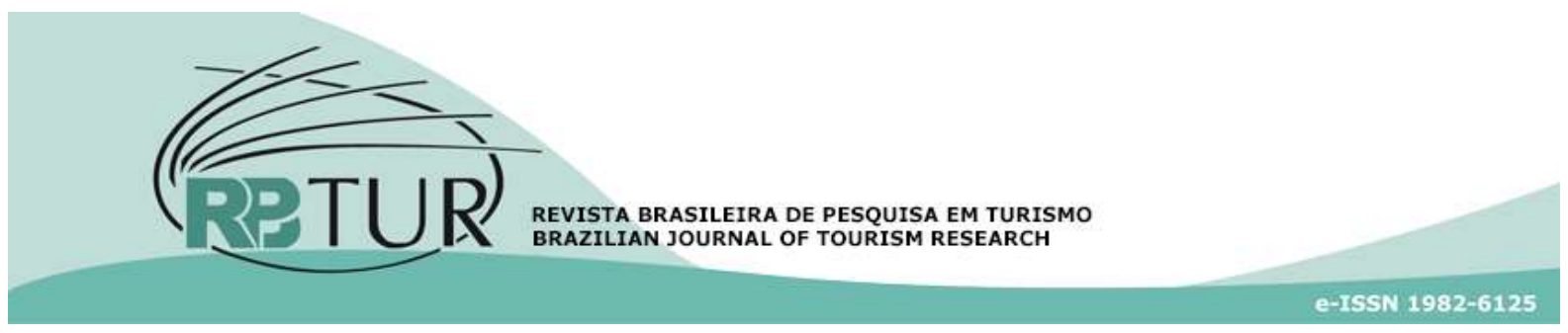

Artigo

DOI: http://dx.doi.org/10.7784/rbtur.v12i3.1416

\title{
O turismo como um instrumento de proteção florestal na Amazônia: uma análise multivariada
}

\section{Tourism as an instrument of forest protection in the Amazon: a mul- tivariate analysis}

\section{El turismo como un instrumento de protección forestal en La Amazo- nía: un análisis multivariante}

\author{
Jefferson Lorencini Gazoni ${ }^{1}$ \\ lara Lucia Gomes Brasileiro²
}

Resumo: Propósito do tema: A crescente demanda internacional por bens primários tem gerado oportunidades excepcionais para a mineração e para o agronegócio na Amazônia. Isto está promovendo, em muitos casos, a perda progressiva da cobertura do solo. Muitas são as estratégias propostas para a contenção do desmatamento regional, ente elas, o turismo, apontado como uma atividade econômica alternativa e mais sustentável para a região. Objetivo: A finalidade deste estudo foi estimar a importância relativa do turismo para o ritmo do desmatamento no bioma Amazônia no período 2015/2016. Metodologia e abordagem: Foram utilizadas séries de corte para as 91 microrregiões geográficas do bioma, nas quais foi aplicada a técnica de regressão linear múltipla associada à decomposição das covariâncias pela Medida de Pratt. Resultados: Os resultados sugerem que o desmatamento é uma função da pecuária bovina, da agricultura, da extração de madeira, dos assentamentos rurais, das áreas protegidas e, entre outros, do turismo. Identificou-se uma correlação inversa entre o turismo e as taxas anuais de desmatamento do bioma. Originalidade: Os resultados deste estudo permitem propor o desenvolvimento responsável do turismo como uma estratégia para a proteção da cobertura florestal da Amazônia.

Palavras-chave: Desenvolvimento regional. Desmatamento. Conservação. Uso do solo.

Abstract: Theme purpose: the growing international demand for primary goods has generated exceptional opportunities for mining and agribusiness in the Amazon. In many cases, this is causing a progressive loss of land cover. Many strategies are proposed to contain regional deforestation, including tourism, which is seen as a

\footnotetext{
${ }^{1}$ Universidade de Brasília (UnB), Brasíli, DF, Brasil. Realizou a revisão da literatura, a organização do banco de dados, a aplicação das técnicas econométricas, a análise dos resultados e a redação do texto.

2 Universidade de Brasília (UnB), Brasília, DF, Brasil. Contribuiu na revisão da literatura, na análise dos resultados e na redação do texto.
}

Artigo recebido em: 06/02/2018. Artigo aceito em: 15/05/2018. 
more sustainable alternative economic activity for the region. Objective: the purpose of this study was to estimate the relative importance of tourism to the deforestation rate rhythm in the Amazon biome in the period of 2015/2016. Methodology and approach: a crossection were used for the 91 geographic micro-regions of the biome, to which multiple linear regression associated to covariance decomposition was applied with Pratt's Measure. Results: the results suggest that deforestation is due to livestock farming, agriculture, logging, rural settlements, protected areas and, among others, tourism. The study identified an inverse correlation between tourism and annual deforestation rates in the biome. Originality: the results of this study allow the proposition of the responsible development of tourism as a strategy for the protection of the forest cover of the Amazon.

Keywords: Regional development. Deforestation. Conservation. Land use.

Resumen: Propósito del tema: La creciente demanda internacional por bienes primarios ha generado oportunidades excepcionales para la mineración y para el agronegocio en la Amazonía. Esto está promoviendo, en muchos casos, la pérdida progresiva de la cobertura del suelo. Muchas son las estrategias propuestas para a contención de la deforestación regional, entre ellas, el turismo, apuntado como una actividad económica alternativa y más sostenible para la región. Objetivo: la finalidad de este estudio fue estimar la importancia relativa del turismo para el ritmo de la deforestación en el bioma Amazónico en el período 2015/2016. Metodología y abordaje: Fueron utilizadas series de corte para las 91 microrregiones geográficas do bioma, en las cuales fueron aplicadas a técnica de regresión linear múltiple asociada a la descomposición de las covarianzas por la Medida de Pratt. Resultados: los resultados sugieren que la deforestación está en función de la pecuaria bovina, de la agricultura, de la extracción de madera, de los asentamientos rurales, de las áreas protegidas y, entre otros, del turismo. Se identificó una correlación inversa entre el turismo y las tazas anuales de la deforestación del bioma. Originalidad: los resultados de este trabajo permiten proponer el desarrollo responsable del turismo como una estrategia para la protección de la cobertura forestal de la Amazonía.

Palabras clave: Desarrollo regional. Deforestación. Conservación. Uso del suelo.

\section{INTRODUÇÃO}

O acelerado crescimento econômico ocorrido a partir de meados do século XX promoveu, em grande parte dos países, uma significativa melhoria na qualidade de vida. Com isso, ampliaram-se as pressões sobre os recursos naturais para intensidades jamais presenciadas (Intergovernmental Panel on Climate Change, 2014). Recentemente, o crescimento econômico de países altamente populosos, como a China, a Índia, e a Rússia (Araújo \& Costa, 2010), muito ampliaram essas demandas, com tendências preocupantes. No Brasil, país historicamente produtor de bens primários, a crescente demanda tem gerado oportunidades excepcionais, principalmente para a minero-siderurgia e para o agronegócio (Almeida \& Marin, 2010). Em muitos casos, no entanto, com ações que causam o desmatamento progressivo do território, como tem ocorrido na Amazônia.

O bioma Amazônia é uma das seis tipologias de domínios da natureza no Brasil, abrangendo uma área de 4,2 milhões de $\mathrm{km}^{2}$, 49,3\% do território nacional (Instituto Brasileiro de Geografia e Estatística, 2005). A população regional atingiu 18,8 milhões de habitantes em 2010 (IBGE - Censo Demográfico, 2010), 9,6\% da população brasileira. Estima-se que a região, um conjunto de ecossistemas diversos (áreas de terra firme, rios e áreas alagadas), abrigue cerca de $30 \%$ das florestas tropicais restantes no planeta (Food and Agriculture Organization of the United 
Nations, 2016), que contém, aproximadamente, $12,5 \%$ de toda a biomassa existente (Baccini, Goetz, Walker, Laporte, Sun, SullaMenashe, \& Samanta, 2012) e que protege cerca de um terço das espécies conhecidas (World Wildlife Fund for Nature, 2013).

O desmatamento pode levar a uma reestruturação das dinâmicas da atmosfera na superfície, tanto na própria região (Spracklen \& Garcia-Carreras, 2015) como num todo (Medvigy, Walko, \& Avissar, 2011). Em nível regional ou local, o desmatamento promove a redução das chuvas e da evapotranspiração, com consequente diminuição da umidade do solo e da superfície (Navarrete, Tsai, Mendes, Faust, Hollander, Cassman, \& Kuramae, 2015), a redução e a contaminação dos recursos hídricos (Lewis, Brando, Phillips, Heijden, \& Nepstad, 2011), com danos à saúde das populações (Hahn, Gangnon, Barcellos, Asner, \& Patz, 2014) além da perda da produtividade dos solos (Lawrence \& Vandecar, 2015) e o significativo dano à biodiversidade (Barlow, Lennox, Ferreira, Berenguer, Lees, Mac Nally, \& Parry, 2016). Registramse, do mesmo modo, problemas socioambientais, como a migração e o crescimento desorganizado das cidades (Caviglia-Harris, Sills, \& Mullan, 2013) e conflitos sociais, seguidos, muitas vezes, de grande violência (Solinge, 2010). Apesar do reconhecimento da sua importância, segundo o Instituto Nacional de Pesquisas Espaciais (INPE), até 2016 foram perdidos 683,0 mil $\mathrm{km}^{2}$ de cobertura florestal, 15,2\% da sua área. Restaram 2,62 milhões $\mathrm{km}^{2}$ de florestas, $62,4 \%$ do território.

É nesse contexto que se aponta o turismo como uma atividade econômica alter- nativa e sustentável para a Amazônia (Oliveira, Silva, Matos, \& Hara, 2010; Peralta, 2012; Doan, 2013; Hoefle, 2016). As alegações são diversas. A presença do turismo pode funcionar como um conjunto fiscalizador da qualidade do meio ambiente (Liu, Qu, Huang, Chen, Yue, Zhao, \& Liang, 2014). O turismo pode ajudar na gestão das áreas protegidas por intermédio do incremento da receita da unidade, como taxas de ingresso, ou um percentual das atividades correlatas (Chen, Nakama, \& Zhang, 2017). Além disso, tem peso político-econômico regional. Ou seja, quanto mais relevante para a economia regional, menores serão as ocupações em outras áreas (Lobo \& Moretti, 2009). No ambiente político, a importância regional do turismo tende a ser inversamente correlacionado ao apoio público a atividades degradadoras dos recursos turísticos, enquanto sua correlação com as políticas ambientais é diretamente proporcional.

Por esses aspectos o presente estudo questiona a relação entre turismo e desmatamento na Amazônia. Qual foi a contribuição do turismo para o desmatamento regional? Por consequência, o objetivo deste trabalho é estimar a importância relativa do turismo para o ritmo do desmatamento no bioma Amazônia no período 20015/2016. Para isto, utilizou-se da técnica de regressão linear múltipla por Mínimos Quadrados Ordinários (Gujarati, 2006; Pindik \& Rubinfeld, 1997) associada à análise da medida de importância relativa de Pratt (1987). O trabalho foi desenvolvido em cinco fases principais: 1 ) revisão da bibliografia sobre o tema; 2 ) construção de uma base de dados de uma série de corte por microrregiões geográficas do bioma 
Amazônia; 3) definição do modelo econométrico para as taxas anuais de desmatamento em razão das forças político-econômicas, incluindo o turismo; 4) estimativa da importância do turismo relativa às outras forças do desmatamento; e 5) discussão dos resultados do modelo.

\section{TURISMO E DESMATAMENTO}

O espaço é um recurso disputado por diversos agentes econômicos. Com o crescimento populacional, tem-se a implantação de infra-estrutura suporte, o crescimento horizontal das cidades, a ampliação constante da área agropecuária, entre outros fatores que ocupam parte do espaço, e não raramente, se sobrepõem a áreas não antropizadas ou ainda detentoras de uma cobertura vegetal representativa e funcional. Entre essas atividades, o turismo tem sua responsabilidade. A urbanização turística por segundas residências, resorts ou outras facilidades, gera ocupação direta de vastas porções territoriais, principalmente no caso do turismo de massa. Além disso, o uso de materiais de construção combinado com o consumo de alimentos e outros bens e serviços, podem promover indiretamente danos à cobertura do solo.

Ao analisar cerca de 1,5 mil publicações a respeito das relações entre o turismo e o meio ambiente, Buckley (2011) identificou que na maioria delas o turismo foi apontado como gerador de impactos nocivos e que em outros casos, o turismo promoveu a conservação. Diversos são os estudos acerca do uso do turismo para a conservação (Nyaupane \&
Poudel, 2011; Brandão, Barbieri, \& Reyes Junior, 2015). Organizações também têm sugerido o desenvolvimento do turismo como uma estratégia para a sustentabilidede ambiental (United Nations Environment Programme, 2005; World Wildlife Fund for Nature, 2003; Instituto Chico Mendes de Conservação da Biodiversidade, 2011; World Tourism Organization, 2002, 2013), embora sejam conhecidos seus potencias impactos nocivos, principalmente aqueles causados pelo turismo de massa em nível local, como o desmatamento.

Apesar de a literatura específica apresentar uma vasta coleção de estudos sobre as relações entre o turismo e o meio ambiente, as pesquisas voltadas ao entendimento das relações específicas com o desmatamento em si são raras. Em geral, as análises sugerem que, se por um lado, o turismo tem apresentado impactos negativos sobre a cobertura do solo em algumas regiões (Araujo, CarvaIho, \& Silva, 2005; Kuvan, \& Akan, 2005; Zhong, Deng, \& Xiang, 2008; Almeyda, Broadbent, Wyman, \& Durham, 2010; Fox, Witz, Blanc, Soulié, Penalver-Navarro, \& Dervieux, 2012), por outro, o turismo tem sido considerado uma força importante na proteção e na regeneração de áreas florestais (Gaughan, Binford \& Southworth, 2009;_Suntikul \& Dorji, 2015; Boavida-Portugal, Rocha \& Ferreira, 2016; Vijay, Kushwaha, Chaudhury, Naik, Gupta, Kumar, \& Wate, 2016). Em geral, o que muda é o contexto local e a forma de turismo praticada.

Ao investigar as mudanças nas pressões causadas pelo turismo sobre as florestas e sobre a vegetação alpina durante cinquenta anos na região do Monte Everest, um dos 
mais importantes destinos de montanhismo do mundo, Stevens (2003) mostrou que o turismo melhorou as condições de vida da população local. Todavia, impactos negativos foram identificados, como os danos à floresta causados por incêndios provocados diretamente pelos visitantes ou pelo uso da madeira para construção de facilidades turísticas. Segundo esse autor, o contínuo uso do fogo não controlado tem contribuído para a redução do diâmetro médio dos troncos em algumas porções territoriais da floresta e perda da cobertura vegetal em outras.

Analisando o uso das florestas com o propósito de desenvolvimento da atividade turística na região de Antalya-Belek, na Turquia, Kuvan (2005) percebeu que a rápida transição para o turismo de massa ocorrida na região não foi acompanhada por políticas públicas ou projetos de proteção e sustentabilidade do desenvolvimento, resultando em problemas nas áreas florestadas. Em particular, a fragmentação florestal e o desmatamento na região têm sido promovidos pela implantação das infra-estruturas e dos equipamentos necessários para a prática do turismo. Nas áreas costeiras, o pesquisador identificou que todas as novas facilidades se desenvolveram sobre antigas áreas florestais.

A Reserva da Biosfera Changbai Mountain na China recebe, anualmente, centena de milhares de turistas. Mas, apesar da sua grande importância econômica e ecológica, tem sofrido com a fragmentação em sua área de amortecimento. Ao estudar a relação do turismo com o desmatamento nessa região, Zhao, Li, Wang e Xu (2011) concluíram que a explosão do turismo não ajudou na redução das pressões sobre a floresta - ao contrário, ampliou a fragmentação nas proximidades da reserva.

Para compreender as relações entre o turismo e as mudanças no uso do solo na bacia do
Rio Li (China) entre 1989 e 2010, Mao, Meng e Wang (2014) utilizaram uma abordagem híbrida com modelagem multi-nível e regressão logística para analisar o potencial de degradação das forças motrizes dessas transformações. Os resultados mostraram que o desenvolvimento acelerado do turismo e a expansão urbana expuseram a área a grande risco de danos ou perda definitiva de sua cobertura vegetal. Ameaças também incluem a implantação de rodovias e a construção de mirantes.

Em síntese, estudos localizados que apontam o turismo como um fator promotor de desmatamento possuem alguns aspectos que merecem destaque. A presença ou a ascensão do turismo de massa nas áreas florestadas gera uma grande pressão que as políticas públicas têm dificuldade em conter ou redirecionar. Outro aspecto importante é a característica pontual dos impactos. Em geral, observam-se impactos diretos localizados, principalmente na implantação de infra-estruturas suporte e equipamentos turísticos, como residências secundárias e outros meios de hospedagem. Por outro lado, afirma-se que o turismo pode promover a prevenção do desmatamento ou permite a recuperação de áreas degradadas (Oosterzee, 2000; Stronza \& Pegas, 2008).

Em um estudo sobre as forças condutoras das mudanças no uso e na cobertura do solo na região de selva em dois municípios do sul do México, Corona, Galicia, Palacio-Prieto, Bürgi e Hersperger (2016) utilizaram imagens de satélite e fotografias aéreas para produzir uma base de dados georreferenciada para os anos de 1985, 1995 e 2006. Um conjunto de técnicas estatísticas foi empregado para identificar as causas diretas e indiretas do desmatamento. Os resultados mostraram que a atividade agropecuária é a mais significativa delas, sendo responsável por aproximadamente $85 \%$ do desmatamento regional. Entretanto, os autores identificaram que o incremento 
das oportunidades de trabalho vinculadas ao setor turístico tem implicado na redução ou no abandono das atividades agropecuárias, favorecendo a regeneração das florestas.

Em outro estudo robusto, Hoang, Vanacker, Van Rompaey, Vu e Nguyen (2014) analisaram as mudanças na cobertura do solo no Distrito de Sa Pa, na China. O turismo internacional iniciou-se em 1993 com a abertura política, alterando profundamente o cotidiano da população residente. Utilizando imagens de alta resolução por satélite de três diferentes períodos e uma análise de covariâncias, os autores investigaram as mudanças na cobertura do solo entre 1993 e 2014 . O estudo mostrou que entre 1993 e 2006 houve aumento do desmatamento causado pelo avanço da área agropecuária. Mas, entre 2006 e 2014 ocorreu o contrário. Os resultados mostraram que o desmatamento é muito menor em áreas que possuem alto grau de envolvimento com as atividades turísticas. Isso ocorreu, segundo os autores, porque com a diversificação das atividades econômicas os proprietários rurais tornaram-se menos dependentes da produção agropecuária. Concluíram, assim, que novos padrões de produção podem gerar redução da pressão sobre as florestas regionais.

Efeitos imprevistos podem afetar significativamente a eficiência de políticas públicas de conservação. Robalino, Pfaff e Villalobos (2015) identificaram que isto tem sido verificado na criação de áreas protegidas na Costa Rica e no consequente aumento do desmatamento nas áreas florestadas adjacentes. Nas áreas mais próximas (de amortecimento), até $10 \mathrm{~km}$ este impacto tem sido mínimo. Entretanto, a pesquisa mostrou que existe grande significância estatística entre o desmatamento e as áreas próximas às rodovias que não contam com o turismo e estão longe da entrada dos parques. A conlcusão do trabalho foi que o aumento do custo de transporte e o desenvolvimento do turismo em suas áreas de influência podem reduzir as taxas de desmatamento na Costa Rica.

Os resultados apresentados na literatura não são conclusivos a respeito da polaridade da relação entre turismo e desmatamento. Em nível local, o turismo, principalmente de massa, vem promovendo o desmatamento de áreas naturais, mas, por outro lado, a alternativa econômica do turismo em relação a outras atividades econômicas mais nocivas tem mostrado resultados significativos, principalmente do ponto de vista macroeconômico.

\section{AMAZÔNIA: AMBIENTE, ECONOMIA E DESMATAMENTO REGIONAL}

Esta seção apresenta uma revisão sobre os principais aspectos relacionados à Amazônia, sua economia (incluindo o turismo) e o desmatamento. Inicialmente destaca as principais características físicas e socioeconômicas regionais. Em seguida, realiza uma revisão da bibliografia sobre as causas do desmatamento. Por ultimo, apresenta o turismo e sua situação na área de estudo. Esses aspectos são fundamentais para a investigação do problema e para a análise dos resultados desta pesquisa.

A Amazônia Continental se estende por nove países da América do Sul: Brasil, Peru, Bolívia, Colômbia, Equador, Venezuela, Guiana, Suriname e Guiana Francesa, associada principalmente às bacias hidrográficas dos rios Amazonas/Solimões e Tocantins, e parte da bacia do rio Orenoco. Por critérios político-administrativos, a área da Amazônia Sul-Americana é de 6,5 miIhões km2 (Albagli, 2001). A superfície amazônica 
é, em grande parte, coberta por florestas densas e abertas, mas também abriga uma diversidade de outros ecossistemas, como florestas de igapó, várzeas, florestas estacionais, campos alagados, savanas e campinaranas (Brasil, 2009). As florestas cobrem 3,6 milhões de $\mathrm{km} 2$, mais de $85 \%$ da superfície desse bioma no Brasil, $69 \%$ da área florestada nacional (Instituto Brasileiro de Geografia e Estatística, 2005). Político-administrativamente, no Brasil o bioma Amazônia está contido nos estados do Acre, Amazonas, Rondônia, Roraima, Amapá, Pará e parte dos estados do Mato Grosso, Tocantins e Maranhão.

A economia sempre esteve voltada a prover produtos primários para a demanda doméstica e internacional, em boa parte, atrelada aos grandes programas de desenvolvimento empreendidos pelo Governo Federal a partir da década de 1960. O Produto Interno Bruto (PIB) regional chegou a R\$ 420,69 bilhões em 2014 (IBGE - Contas Nacionais, 2014). Atividade tradicional desde a chegada dos europeus no século XVI, a agropecuária tornou-se, nos últimos anos, a principal atividade socioeconômica da Amazônia e a responsável por grande parte das transformações ocorridas no uso do solo e na cobertura vegetal regional. A área colhida em 2016 foi de 162,3 mil $\mathrm{km}^{2}$, uma média de 1,8 mil $\mathrm{km}^{2}$ por microrregião geográfica (IBGE - Pesquisa da Produção Agrícola, 2016). Apesar dessa presença agrícola, sem dúvida a principal atividade em relação à área utilizada é a pecuária bovina de corte. Atualmente, a região conta com um rebanho bovino de aproximadamente 78 milhões de cabeças (IBGE - Pesquisa Pecuária Municipal, 2016).

Além da agropecuária, o extrativismo vegetal é outra atividade econômica importante para a região. Em 2016 foram produzidos 10,54 milhões de $\mathrm{m}^{3}$ de madeira em tora (IBGE - Produção da Extração Vegetal e da Silvicultura, 2016). Aliada à produção de madeira em tora está a produção de carvão que, muitas vezes, agrega valor a madeira, ampliando o lucro dos exploradores. Apesar de a atividade madeireira ser uma importante fonte de renda e empregos na Amazônia, seu crescimento preocupa, pois se supõe que a área de exploração madeireira pode ser tão extensa quanto a que é desmatada anualmente na Amazônia, incluindo em áreas protegidas (Nepstad, Verssimo, Alencar, Nobre, Lima, Lefebvre, \& Cochrane, 1999; Uhl \& Vieira, 1989), o que promove outros danos diretos e indiretos dessa atividade aos ecossistemas. O avanço dessa fronteira agropecuária tem sido contido, principalmente, pelas áreas protegidas que cobrem grande parte da região (Gazoni \& Mota, 2010a).

Áreas protegidas são espaços territoriais sob algum regime especial de proteção. Na Amazônia são muitos os tipos de áreas protegidas: Áreas de Preservação Permanente, Reservas Legal, Terras Indígenas, Terras Quilombolas, áreas militares e, entre outras, as Unidades de Conservação da Natureza. Segundo o Cadastro Nacional de Unidades de Conservação do Ministério do Meio Ambiente, a Amazônia contava até julho de 2017 com 334 Unidades de Conservação que totalizam uma cobertura de $1.166 \mathrm{mil} \mathrm{km}^{2}$, $27,89 \%$ da sua superfície territorial. São 85 unidades de proteção integral com 430,2 mil $\mathrm{km}^{2} ; 249$ unidades de uso sustentável com 736,0 mil km². Além disso, as Terras Indígenas cobrem uma área de $731,8 \mathrm{mil} \mathrm{km}^{2}$, ou seja, $14,1 \%$ do território regional

O resultado do somatório das forças econômicas, sociais, físicas e políticas no território amazônico tem transformado significativamente a região (Becker, 2004). Um dos 
resultados mais acompanhados dessas transformações é a contínua perda da sua cobertura florestal por meio do desmatamento provocado, geralmente, pelo corte raso (estágio extremo do desmatamento, em que o padrão observado representa a retirada completa da vegetação original) ou por queimadas e incêndios (Food and Agriculture Organization of the United Nations, 2016).

O comportamento das taxas anuais de desmatamento na Amazônia seguiu, nos últimos vinte anos, um padrão cíclico, com máximas em 2002 (21.393 km²), 2003 (25.247 $\mathrm{km}^{2}$ ) e $2004\left(27.772 \mathrm{~km}^{2}\right)$, e mínimas em $2012\left(4.571 \mathrm{~km}^{2}\right), 2013\left(5.891 \mathrm{~km}^{2}\right)$ e 2014 $\left(5.012 \mathrm{~km}^{2}\right)$. De acordo com o Instituto Nacional de Pesquisas Espaciais (INPE), em 2016 o desmatamento atingiu 7. $647 \mathrm{~km}^{2}$. Muitas são as causas apontadas para o desmatamento presentes na literatura nacional e internacional. Entretanto, devido a diversos fatores, como a baixa qualidade dos dados sobre o desmatamento, principalmente até o final da década de 1990, a grande maioria dos estudos realizados até então carece de profundidade. Além disso, o desmatamento não segue um único padrão preestabelecido, mas múltiplos processos, dependendo do tempo e do espaço. Assim, permaneceram muitas controvérsias sobre alguns fatores determinísticos do desmatamento regional e sobre a contribuição de cada fator para a destruição florestal.

O Quadro 1 arrola os fatores intervenientes no desmatamento regional segundo diversos autores. Os principais aspectos explicativos do desmatamento já identificados na Amazônia são: 1) os populacionais - densidade demográfica, população urbana e rural, migração e crescimento das áreas urbanas; 2) a agropecuária - produção agrícola, cultivo de soja, rebanho bovino e pastagens e titularidade da terra; 3 ) as políticas de acesso densidade de rodovias, implantação e pavimentação de estradas, distância das rodovias; 4) o mercado - preços dos produtos agrícolas, preço da terra e custo de transporte; 5 ) o extrativismo vegetal - madeira em tora, carvão vegetal e extrativismo não madeireiro; 6) as políticas ambientais - áreas protegidas e fiscalização ambiental; 7) o ambiente biofísico - estoque florestal, fertilidade do solo, pluviosidade e efeito $\mathrm{El} \mathrm{Niño}^{3}$; 8) a mineração - distância dos centros de produção mineral; 9) os assentamentos rurais - número de famílias assentadas e tamanho dos lotes; 10) outros aspectos - crédito rural, projetos públicos de desenvolvimento e grilagem das terras públicas.

Quadro 1 - Aspectos explicativos do desmatamento segundo diferentes autores

\footnotetext{
${ }^{3}$ Fenômeno caracterizado por alterações significativas de curta duração na distribuição da temperatura da
}

superfície da água do Oceano Pacífico Sul, com profundos efeitos no clima no Brasil. 
Gazoni, J. L. ; Brasileiro, I. L. G.

O turismo como um instrumento de proteção florestal na Amazônia: uma análise multivariada

\begin{tabular}{|c|c|c|c|}
\hline $\begin{array}{l}\text { Área de } \\
\text { estudo }\end{array}$ & Período & Aspectos explicativos* & Fontes \\
\hline Amazônia & Até 1985 & $\begin{array}{l}\text { População (+); área plantada (+); rebanho bovino (+); } \\
\text { produção de madeira (+); densidade rodoviária (+); } \\
\text { distância da capital estadual (-). }\end{array}$ & Reis \& Margulis (1991) \\
\hline $\begin{array}{l}\text { Amazônia } \\
\text { Central }\end{array}$ & Até 2000 & $\begin{array}{l}\text { Distância a rodovias }(-) \text {, área de pastagens }(+) \text {, reba- } \\
\text { nho bovino }(+) \text {, titularidade da terra }(-) \text { e renda }(-)\end{array}$ & $\begin{array}{l}\text { Walker, Perz, Caldas \& Silva } \\
\text { (2002) }\end{array}$ \\
\hline Amazônia & 1970/1996 & $\begin{array}{l}\text { Pecuária }(+) \text {, agricultura }(+) \text {, madeira }(+) \text {, mineração } \\
(+) \text { e titularidade da terra }(-)\end{array}$ & $\begin{array}{l}\text { Andersen, Granger, Reis, } \\
\text { Weinhold, \& Wunder (2002) }\end{array}$ \\
\hline Amazônia & $1975 / 1985$ & $\begin{array}{l}\text { Preços dos produtos agrícolas }(+) \text {; } \\
\text { preço da terra }(+) \text {; crédito rural }(+) \text {; implantação de } \\
\text { estradas }(+) \text {; renda dos estabelecimentos rurais }(-)\end{array}$ & Young (1998) \\
\hline Amazônia & $1968 / 1987$ & $\begin{array}{l}\text { Implantação de rodovias }(+) \text {; rodovias } \\
\text { pavimentadas }(+)\end{array}$ & Pfaff (1999) \\
\hline Amazônia & $1978 / 1988$ & $\begin{array}{l}\text { Crescimento das áreas de pastagens }(+) \text {; crescimento } \\
\text { da área agrícola }(+) \text {; exploração de madeira }(+) \text {; } \\
\text { áreas de mineração }(+) \text {; crescimento das áreas urba- } \\
\text { nas }(+)\end{array}$ & $\begin{array}{l}\text { Skole, Chomentowski, Salas, } \\
\text { \& Nobre, (1994) }\end{array}$ \\
\hline Amazônia & $1985 / 1995$ & $\begin{array}{l}\text { Produção agrícola (+). Obs.: A inovação tecnológica } \\
\text { na agricultura gera menores desmatamentos }\end{array}$ & Cattaneo (2005) \\
\hline Rondônia & $1980 / 2000$ & $\begin{array}{l}\text { Assentamentos rurais }(+) \text {; o tamanho dos lotes }(+) \text {, o } \\
\text { tempo de ocupação }(+) \text {, a infraestrutura }(+) \text {, as reser- } \\
\text { vas florestais de uso comum (-) }\end{array}$ & Batistella \& Moran (2005) \\
\hline Amazônia & $1997 / 2000$ & $\begin{array}{l}\text { Área de Reservas Extrativistas (-); área de Parques } \\
\text { Nacionais (-); Área de Terras Indígenas (-) }\end{array}$ & $\begin{array}{l}\text { Nepstad, Schwartzman, } \\
\text { Bamberger, Santilli, Ray, } \\
\text { Schlesinger \& Rolla (2006) }\end{array}$ \\
\hline Amazônia & $2000 / 2001$ & $\begin{array}{l}\text { Densidade populacional }(+) \text {; rodovias }(+) \text {; severidade } \\
\text { da estação de seca }(+)\end{array}$ & $\begin{array}{l}\text { Laurance, Albernaz, Schroth, } \\
\text { Fearnside, Bergen, Venticin- } \\
\text { que \& Costa (2002) }\end{array}$ \\
\hline $\begin{array}{l}\text { Uruará } \\
\text { (PA) }\end{array}$ & Até 2005 & $\begin{array}{l}\text { Distância da rodovia Transamazônica (-); número } \\
\text { de homens nos estabelecimentos rurais (+); fertili- } \\
\text { dade do solo }(+) \text {; crédito (+) }\end{array}$ & $\begin{array}{l}\text { Caldas, Walker, Arima, Perz, } \\
\text { Aldrich \& Simmons (2007) }\end{array}$ \\
\hline Amazônia & $1996 / 2006$ & $\begin{array}{l}\text { Distância das rodovias (-); áreas protegidas (-); } \\
\text { efeito El Niño (+) }\end{array}$ & $\begin{array}{l}\text { Adeney, Christensen \& } \\
\text { Pimm (2009) }\end{array}$ \\
\hline $\begin{array}{l}\text { Amazônia } \\
\text { Oriental }\end{array}$ & $2007 / 2008$ & $\begin{array}{l}\text { Agropecuária (+); madeira (+); carvão (+); extrati- } \\
\text { vismo vegetal não madeireiro (-); distância do es- } \\
\text { critório regional do IBAMA mais próximo (-); e } \\
\text { áreas protegidas (-). }\end{array}$ & Gazoni \& Mota (2010b) \\
\hline Pará & $2006 / 2010$ & $\begin{array}{l}\text { Assentamentos rurais }(+) \text {; incertezas fundiárias (+); } \\
\text { infra-estrutura }(-) \text {; tamanho dos lotes }(-) \text {; madeira } \\
(+)\end{array}$ & $\begin{array}{l}\text { Calandino, Wehrmann, \& } \\
\text { Koblitz (2012) }\end{array}$ \\
\hline Amazônia & $2003 / 2008$ & $\begin{array}{l}\text { Pecuária }(+) \text {; agricultura }(+) \text {; madeira }(+) \text {; assenta- } \\
\text { mentos rurais }(+) \text {; áreas protegidas }(-) \text {; fiscalização } \\
\text { ambiental }(-) \text {. }\end{array}$ & Gazoni (2014) \\
\hline Amazônia & $1999 / 2011$ & $\begin{array}{l}\text { Preços agrícolas }(+) \text {; crédito rural (+); custo de } \\
\text { transporte (=). fiscalização (-) }\end{array}$ & Ferreira \& Coelho (2015) \\
\hline $\begin{array}{l}\text { Amazônia } \\
\text { (arco) }\end{array}$ & $2008 / 2012$ & $\begin{array}{l}\text { Pecuária (+), lavoura permanente }(+) \text {; lavoura tem- } \\
\text { porária }(+) \text {; Produto Interno Bruto }(+) \text {; população } \\
(+) \text {; educação }(-)\end{array}$ & Delazeri (2016) \\
\hline $\begin{array}{l}\text { Amazônia } \\
\text { (UCs) }\end{array}$ & $2015 / 2016$ & $\begin{array}{l}\text { Densidade florestal (+), Estação Ecológica (-), Pará } \\
(+) \text {, visitação pública manejada (-) }\end{array}$ & Gazoni (2018) \\
\hline
\end{tabular}

* correlação positiva (+); correlação negativa (-) 
A redução significativa do ritmo do desmatamento da Amazônia é imperativa. Se, por um lado, as pressões aumentam sobre os governos, provenientes de diversos agentes sociais locais, nacionais e internacionais, por outro, há uma forte resistência por parte dos grupos beneficiados pela atual situação de contínua destruição. Neste contexto, são muitas as propostas e estratégias que têm sido utilizadas, com maior ou menor grau de sucesso. Entre elas: a criação de áreas protegidas de diversos tipos, o aumento na intensidade e frequência da fiscalização ambiental, implantação de novas legislações e o desenvolvimento do turismo. Apesar de o turismo estar presente em parte das políticas de conservação, é inegável seu potencial de geração de impactos nocivos aos ecossistemas e/ou às sociedades, principalmente em nível local. Por isso, é preciso ter cuidado na interpretação dos resultados das pesquisas e, principalmente, na elaboração de políticas de conservação ou de desenvolvimento.

A Tabela 1 destaca os equipamentos e serviços turísticos que estavam cadastrados no Ministério do Turismo (MTur) em 31 de dezembro de 2014 nos nove estados que envolvem a Amazônia. O estado com a maior oferta de hospedagem é o Mato Grosso, com 21,6 mil leitos cadastrados, ou seja, $24,3 \%$ do total. A segunda maior oferta de leitos encontra-se no estado do Amazonas. São 20,2 mil leitos, $22,7 \%$ da oferta regional. O Pará detém outra parcela importante da oferta, com 15,4 mil leitos (17,3\%). Além desses, o Maranhão oferta 13,5 mil leitos (15,2\%), o Acre 6,3 mil leitos (7,1\%), o Tocantins 5,9 mil leitos (6,6\%), Rondônia atende 4,1 mil leitos $(4,6 \%)$, Roraima, apresenta 1,2 mil leitos (1,3\%) e o Amapá conta com 859 leitos, apenas $0,9 \%$ da oferta regional cadastrada (Brasil, 2015). A oferta de hospedagem é o principal indicador da distribuição espacial da demanda turística regional. É claro que estes números são apenas indicadores, já que o número de equipamentos em funcionamento é bem maior que o número de empresas cadastradas.

Tabela 1 - Equipamentos e serviços turísticos na Amazônia cadastrados no MTur

\begin{tabular}{|c|c|c|c|c|c|c|c|c|c|c|}
\hline \multirow{2}{*}{\multicolumn{2}{|c|}{ Oferta }} & \multicolumn{9}{|c|}{ Unidade da Federação } \\
\hline & & $A C$ & AP & AM & PA & RO & $\mathrm{RR}$ & TO & MA & MT \\
\hline & $\mathrm{N}$ & 86 & 13 & 224 & 161 & 48 & 16 & 122 & 144 & 295 \\
\hline \multirow[t]{2}{*}{ Hotéis e similares } & UH's (mil) & 2,3 & 0,5 & 9,8 & 7,3 & 1,8 & 0,5 & 2,7 & 6,4 & 10,4 \\
\hline & leitos (mil) & 6,3 & 0,9 & 20,2 & 15,4 & 4,1 & 1,2 & 5,9 & 13,5 & 21,6 \\
\hline \multicolumn{2}{|l|}{ Agências } & 71 & 70 & 235 & 254 & 133 & 40 & 57 & 203 & 285 \\
\hline \multicolumn{2}{|c|}{ Restaurantes, bares e similares } & 111 & 2 & 25 & 83 & 13 & 23 & 42 & 13 & 197 \\
\hline \multicolumn{2}{|c|}{ Transportadoras turísticas } & 8 & 2 & 55 & 53 & 19 & 4 & 28 & 45 & 206 \\
\hline \multicolumn{2}{|c|}{ Locadoras de veículos } & 10 & 4 & 5 & 6 & 3 & 2 & 1 & 7 & 33 \\
\hline \multicolumn{2}{|c|}{ Organizadoras de eventos } & 10 & 14 & 40 & 51 & 5 & 20 & 10 & 35 & 34 \\
\hline
\end{tabular}

Fonte: Brasil (2015) 
Região de dimensões continentais, a Amazônia apresenta um conjunto de recursos naturais e culturais com grande potencial de aproveitamento turístico. Entretanto, uma parte desses recursos está sendo ameaçada, devido à expansão de outras atividades econômicas como a agropecuária e a extração de madeira sem o adequado manejo, o que tem causado a perda da cobertura do solo, entre outros impactos negativos como a poluição dos cursos d'água e do ar. Dessa forma, apesar do processo de desenvolvimento do turismo na Amazônia estar em seus estágios iniciais, sua capacidade como alternativa econômica para a região exige uma investigação das suas relações com o fenômeno do desmatamento na Amazônia.

\section{METODOLOGIA}

Metodologicamente, para estimar a importância relativa do turismo para o desmatamento regional, utilizou-se da técnica de regressão múltipla por Mínimos Quadrados Ordinários (MQO) combinada com a decomposição das covariâncias por meio da Medida de Pratt (1987). A base de dados foi construída com informações obtidas de órgãos oficiais do governo brasileiro.

As informações sobre os desmatamentos na Amazônia foram obtidas pelo Programa de Cálculo do Desflorestamento da Amazônia (PRODES) do Instituto Nacional de Pesquisas Espaciais (INPE). A partir de 2003, o INPE adotou o processo de interpretação assistida por computador denominado Programa PRODES Digital para distingui-lo do processo anterior, com evidentes melhorias na qualidade dos dados a partir de então.
Além dos desmatamentos por microrregião geográfica de 2003 a 2016, foram acessados da base de dados do INPE o desmatamento acumulado e a área florestada em 2016. A base de dados do Instituto Brasileiro de Geografia e Estatística (IBGE) abastece grande parte das variáveis utilizadas nesta pesquisa. A Pesquisa da Pecuária Municipal (PPM) forneceu dados do rebanho bovino. Da Pesquisa da Produção Agrícola (PPA), foi utilizada a área colhida nas lavouras permanentes e temporárias. Da Pesquisa do Extrativismo Vegetal e da Silvicultura, obteve-se a quantidade produzida de madeira em tora. Da base de dados do Ministério do Meio Ambiente (MMA), foram obtidas as malhas digitais das Unidades de Conservação de proteção integral e de uso sustentável (federais e estaduais), das Terras Indígenas e da malha rodoviária. Do Ministério do Desenvolvimento Agrário (MDA), obteve-se o número de famílias residentes em assentamentos por município. A base de dados do Instituto de Pesquisa Econômica Aplicada (IPEA) forneceu informações sobre a distância da capital estadual e o custo de transporte à cidade de São Paulo, aspectos fundamentais para a compreensão da distribuição espacial das taxas de desmatamento regional. Por fim, do Ministério do Turismo (MTur) obteve-se o número de leitos em meios de hospedagem, variável que foi utilizada como indicador da demanda turística nesta pesquisa.

A regressão múltipla é uma técnica de análise multivariada de dados que permite descrever, por intermédio de um modelo matemático, as relações entre duas ou mais variáveis explicativas e determinado fenômeno (Woodridge, 2010). O termo regressão foi in- 
troduzido na literatura específica por Francis Galton (1886). Seu principal objetivo é encontrar relações para possibilitar a estimação dos valores da variável dependente em função do comportamento de duas ou mais variáveis explicativas. $\mathrm{O}$ seu modelo genérico para $p$ variáveis explicativas é representado pela equação (1).

$$
\begin{gathered}
y_{i}=b_{0}+\sum_{j=1}^{p} b_{j} x_{j i}+ \\
\mu_{i} \quad j=1, \ldots, p .
\end{gathered}
$$

Nela, y é a variável dependente; $x_{j}$ são as variáveis explicativas ou independentes; $b$ são os parâmetros da regressão, sendo $b_{0} o$ coeficiente linear e $b_{j}$ os coeficientes angulares; e $\mu_{i}$ o resíduo da regressão, ou seja, a diferença entre as observações reais e os valores estimados pelo modelo para cada observação da amostra. Para isso, são utilizadas técnicas diversas, como o Método dos Mínimos Quadrados Ordinários. O MQO impõe que, dadas $n$ observações de $y$ e $x_{j}$, as estimativas dos parâmetros $\hat{b}_{0}$ e $\hat{b}_{j}$ são escolhidas da forma que a soma dos quadrados dos resíduos, $S Q R=\sum_{i=1}^{n}\left[y_{i}-\hat{y}_{i}\right]^{2}$, adquira o menor valor possível.

Diferente da regressão simples, na regressão com múltiplas variáveis explicativas, com frequência, não se pode medir imediatamente o efeito individual de cada uma dessas variáveis sobre o comportamento da variável explicada, mas apenas abordar seu efeito conjunto. Esse problema é comumente relacionado à presença de multicolinearidade (Gujarati, 2006). Por isso, diversas técnicas têm sido utilizadas para a mensuração do peso de cada variável, entretanto, a grande maioria apresenta deficiências (Green, Carroll e Desarbo, 1978). Uma medida de importância relativa amplamente aceita é a proposta por Pratt (1987). A Medida de Pratt $(\hat{\delta})$ é destacada pela equação $\hat{\delta}_{x_{j}, x_{k}}=\hat{\beta}_{j}^{*} \rho_{j} / \hat{\beta}_{k}^{*} \rho_{k}$, j e $k=1, \ldots, p$. Nela, $\hat{\delta}_{x_{j}, x_{k}}$ é a importância de $x_{j}$ em relação à $x_{k}$; $\rho_{j}$ e $\rho_{k}$ são as respectivas correlações de $x_{j}$ e $x_{k}$ com a variável explicada. Recentemente, Thomas, Zhu e Decady (2007) afirmaram que a fórmula de Pratt é a única que satis (1) emanda natural para a medida, incluindo sua invariância a transformações lineares. A variância dos estimadores de importância relativa $\widehat{V}\left(\hat{\delta}_{j}\right)$ pode ser calculada por meio da equação (2).

$$
\widehat{V}\left(\hat{\delta}_{j}\right)=\frac{\widehat{\delta}_{j}^{2}}{t_{j}^{2}}+\frac{\left[\frac{\left(1-R^{2}\right)}{R^{2}}\right]\left[\frac{\widehat{\beta}_{j}^{* 2}}{R^{2}}+2\left(\widehat{\delta}_{j}-2 \widehat{\delta}_{j}^{2}\right)\right]}{(N-p-1)}+\frac{\left(\frac{\widehat{\beta}_{j}^{* 2}}{R^{2}}-\widehat{\delta}_{j}^{2}\right)}{N}
$$

Os intervalos de $95 \%$ de confiança foram estimados para a Medida de Influência Relativa de Pratt $\left(\hat{\delta}_{j}\right)$ de cada variável explicativa $x_{j}$, que é dada, para os limites superiores e inferiores, por $\hat{\delta}_{j}^{v}=\hat{\delta}_{j} \pm Z_{\frac{\alpha}{2}}\left[\widehat{V}\left(\hat{\delta}_{j}\right)\right]^{\frac{1}{2}}, j=$ $1, \ldots, p$. onde, $Z_{\alpha / 2}$ é o valor do ponto superior com percentual de $\alpha / 2$ na distribuição normal. Por meio de simulações $(N \rightarrow \infty)$, os autores mostraram que as estimativas realizadas por esses procedimentos são muito precisas para amostras superiores a 250 unidades e precisas para amostras acima de cem unidades. Todavia, deve-se considerar que esse é um estudo estatístico, seus resultados representam as probabilidades estimadas e 
não a realidade em si.

\section{O TURISMO E A PROTEÇÃO FLORESTAL NA AMAZÔNIA}

Esta seção apresenta e discute a estimativa das importâncias relativas dos fatores político-econômicos do desmatamento no bioma Amazônia em 2015/2016. Contudo, outros aspectos básicos das suas inter-relações com variáveis explicativas não diretamente causais e consequentemente, excluídas do modelo, devem ser observados para contribuir com a análise dos resultados.

Os aspectos físicos são a base sobre a qual se desenvolvem as políticas e as atividades econômicas e, consequentemente, o desmatamento regional. Além das variáveis que foram inseridas no modelo final, pode-se verificar outros aspectos espacialmente correlacionados ao desmatamento, mas desnecessários aos objetivos desta pesquisa: a precipitação média anual (-); a área dos corposd'água (-); a área florestada (+). Além dessas, a localização dos mercados aos quais se destinam os produtos da agroindústria amazônica parece ser fundamental, principalmente: a distância das sedes municipais das respectivas capitais estaduais (-) e o custo de transporte da microrregião à cidade de São Paulo (-). Os acessos, especialmente os rodoviários, são imprescindíveis para o uso do solo e da sua cobertura em qualquer espaço geográfico. Dois aspectos mostraram-se relevantes para o desmatamento: a densidade rodoviária (federal e estadual) e a distância à rodovia pavimentada mais próxima. Tanto a implantação como a pavimentação de estradas parece ser determinante para o aumento nas taxas de desmatamento anuais. Os efeitos dessas variáveis foram extraídos do modelo econométrico.

O modelo definitivo utilizou as taxas espaciais para reduzir a multicolinearidade entre os fatores. Além disso, as variáveis foram escalonadas de 0 a 1 para eliminar os efeitos das diferenças entre as escalas de medida. Para medir a qualidade do ajustamento da regressão, as medidas mais comumente utilizadas na regressão múltipla e aqui utilizadas foram: o coeficiente de determinação $R^{2}$ ajustado, que mede a proporção da variância da variável dependente, que é explicada pela reta de regressão; pelo erro-padrão da estimativa; e pelo teste F-ANOVA, que testa o efeito conjunto das variáveis independentes sobre a variável dependente. Além disso, as significâncias estatísticas das variáveis foram medidas pelos seus erros-padrão e seus testes $t$, que destacam a probabilidade de seus coeficientes serem estatisticamente nulos.

Para o pressuposto de ausência de colinearidade perfeita, foram utilizados principalmente os testes Tolerância (TOL $\geq 0,963)$, Fator de Inflação do Valor (VIF $\leq 1,038$ ) e o Índice de Condição $(\mathrm{Cl} \leq 3,854)$. A presença de heteroscedasticidade dos resíduos foi regeitada por meio do Teste de Breusch-Pagan ( $p$ valor $=0,254)$. Finalmente, a normalidade na distribuição dos resíduos não pode ser descartada de acordo com os resultados do Teste de Kolmogorov-Smirnov ( $Z=0,823$; $S i g=0,423)$. Por esses aspectos, os estimadores aqui apresentados podem ser considerados os melhores estimadores não tendenciosos (Best Unbiased Estimators - BUE). Os resultados da regressão múltipla por Mínimos Quadrados Ordinários das taxas de desmata- 
mento em função de aspectos políticoapresentados pela Tabela 2 . econômicos para o período 2015/2016 são

Tabela 2 - Resultados para o modelo de regressão por MQO*

\begin{tabular}{|c|c|c|c|c|c|c|c|c|c|}
\hline \multirow[t]{2}{*}{ Modelo } & \multicolumn{2}{|c|}{$\begin{array}{l}\text { Coef. não pa- } \\
\text { dronizado }\end{array}$} & \multirow{2}{*}{$\begin{array}{c}\begin{array}{c}\text { Coef.pa- } \\
\text { dronizado }\end{array} \\
\beta^{*}\end{array}$} & \multirow[b]{2}{*}{$\mathbf{t}$} & \multirow[b]{2}{*}{ Sig. } & \multicolumn{2}{|c|}{$\begin{array}{c}\text { Intervalo de } \\
\text { confiança de } \\
95 \% \text { para } \beta\end{array}$} & \multicolumn{2}{|c|}{$\begin{array}{l}\text { Diagnóstico de } \\
\text { colinearidade }\end{array}$} \\
\hline & $b$ & ep & & & & INF & SUP & TOL & VIF \\
\hline Constante & $-6,860$ & - & - & $-28,447$ & 0,000 & $-7,340$ & $-6,380$ & - & - \\
\hline Pecuária** $^{* *}$ & 0,302 & 0,039 & 0,318 & 7,718 & 0,000 & 0,224 & 0,380 & 0,990 & 1,010 \\
\hline Agricultura $^{* *}$ & 0,159 & 0,026 & 0,251 & 6,059 & 0,000 & 0,107 & 0,211 & 0,976 & 1,025 \\
\hline Ext. Madeira** & 0,151 & 0,026 & 0,237 & 5,705 & 0,000 & 0,098 & 0,204 & 0,970 & 1,031 \\
\hline Assentamentos ${ }^{* *}$ & 0,246 & 0,036 & 0,283 & 6,822 & 0,000 & 0,174 & 0,318 & 0,974 & 1,027 \\
\hline Áreas Protegidas & $-0,304$ & 0,041 & $-0,309$ & $-7,468$ & 0,000 & $-0,385$ & $-0,223$ & 0,981 & 1,020 \\
\hline Turismo & $-0,271$ & 0,047 & $-0,242$ & $-5,830$ & 0,000 & $-0,364$ & $-0,179$ & 0,971 & 1,030 \\
\hline Maranhão & 1,011 & 0,109 & 0,387 & 9,262 & 0,000 & 0,794 & 1,229 & 0,963 & 1,038 \\
\hline Pará & 0,654 & 0,098 & 0,275 & 6,686 & 0,000 & 0,459 & 0,848 & 0,992 & 1,008 \\
\hline
\end{tabular}

${ }^{*}$ Variável dependente: desmatamento ${ }^{* *}$

${ }^{* *}$ Variável transformada pelo logaritmo natural

Aparecem os coeficientes lineares (b) e seus erros-padrão (ep), o coeficiente padronizado $\left(\beta^{*}\right)$, o teste t-studart, o intervalo de confiança para os coeficientes lineares, e o diagnóstico de colinearidade, que apresenta o valor de tolerância (TOL) e o valor do fator de inflação (VIF). A sumarização do modelo, desenvolvido com auxílio do software Statistical Package for Social Sciences (SPSS), apresentou um coeficiente de determinação $R^{2}$ ajustado de 0,849 . Ou seja, as variáveis inseridas no modelo são capazes de explicar $84,9 \%$ do comportamento do desmatamento. Para os casos individuais, as microrregiões geográficas, o erro padrão desta estimativa é de 0,358. A matriz ANOVA destacou os resultados do teste $\mathrm{F}$ de Fisher $(66,971)$ para oito graus de liberdade. Os resultados dos testes estatísticos evidenciaram a boa qualidade do ajustamento, o que se refletiu nos estreitos intervalos de confiança.
Para a estimação do modelo algumas taxas espaciais foram transformadas pelo logaritmo natural. Isto se deu devido a essas variáveis terem apresentado forte assimetria à direita. Com o procedimento, as séries adquiriram comportamento normal, atendendo à pressuposição da análise multivariada. Os resultados mostram que o desmatamento ocorrido no período 2015/2016 nas microrregiões do bioma Amazônia é explicado, entre outras possibilidades, por oito variáveis: 1) o número de cabeças de bovinos; 2 ) a área colhida em lavouras temporárias e permanentes; 3 ) a quantidade produzida de madeira em tora; 4) o número de famílias existentes nos assentamentos rurais; 5) a extensão das áreas protegidas; 6) o número de leitos em meios de hospedagem; 7) a localização no estado do Pará e no estado do Maranhão. O ritmo do desmatamento aumenta na medida em que aumentam a pecu- 
ária bovina, a agricultura, a extração de madeira e os assentamentos rurais. Por outro lado, os resultados sugerem que o ritmo do desmatamento diminui quando aumenta a extensão territorial das áreas protegidas (Unidades de Conservação e Terras Indígenas) e quando aumenta a atividade turística, não havendo aqui distinção quanto a forma de turismo exercida. Evidentemente, é importante uma gestão eficiente quanto aos aspectos socioambientais do turismo, principalmente em nível local. Além disso, os resultados sugerem que, se a microrregião estiver localizada nos estados do Pará ou do Maranhão, o ritmo do desmatamento tende a ser muito maior.

Esses resultados reforçam as conclusões de Reis e Margulis (1991) e de Gazoni (2014) sobre a pecuária bovina, de Cattaneo (2005) e de Young (1998) em relação à agricultura, de Skole et al. (1994) e de Gazoni e Mota (2010b) sobre a extração de madeira, e de Batistella e Moran (2005) e de Caldas et al. (2007) acerca dos assentamentos rurais. As áreas protegidas corroboram com aos resultados de Adeney, Christensen e Pimm (2009) e de Nepstad et al. (2006). Além disso, a importante presença das variáveis dicotômicas para os Estados do Maranhão e do Pará não é novidade. Muitas foram as ocorrências nos últimos anos relativas à gestão ambiental nesses estados (Luíse, 2011; Linhares Jr., 2014). Já o turismo, não foi localizado em nenhum estudo robusto para a Amazônia. Sugere-se que esta variável deva ser incluída para auxiliar a explicação do desmatamento regional nos futuros estudos para este fim.
Os coeficientes lineares (b) permitem a estimativa das elasticidades entre o desmatamento e as variáveis explicativas do modelo. A elasticidade (E) apresenta a estimativa de quanto uma mudança percentual na variável independente representa em termos de variação percentual na variável dependente. Em geral, as elasticidades encontradas são baixas. A elasticidade da pecuária $(0,302)$ em relação ao desmatamento sugere que um aumento de $10 \%$ no rebanho bovino da Amazônia representa um aumento de 3,02\% nas taxas anuais de desmatamento. A elasticidade da agricultura $(0,159)$ evidencia que um aumento de $10 \%$ na área de lavouras implica em um crescimento de apenas $1,59 \%$ nas taxas de desmatamento. A madeira $(0,151)$ também apresenta baixa elasticidade, ou seja, um incremento de $10 \%$ na produção de madeira representa um aumento de 1,51\% na área desmatada. Os assentamentos $(0,246)$ apresentam uma elasticidade um pouco maior. Um acréscimo de $10 \%$ no número de famílias assentadas implica na ampliação de 2,46\% nas taxas de desmatamento. Se por um lado, essas baixas elasticidades permitem pequenas flutuações nas produções com baixos danos, por outro, políticas públicas de restrição dessas atividades também deverão apresentar baixa eficiência.

A agropecuária é uma atividade muito heterogênea na Amazônia, formada pela criação bovina, principalmente para corte, mas também leiteira, e por lavouras permanentes e temporárias diversas, voltadas tanto para o mercado internacional como para o nacional, regional e local, exercida por agricultores familiares (subsistência ou empresarial) ou não, em pequenos ou 
grandes empreendimentos. Um dos maiores problemas relacionados à atividade é a sua mobilidade para a ocupação de áreas antes florestadas, especialmente junto às frentes pioneiras (Margulis, 2003).

Além da da agropecuária, a exploração e o processamento de madeira é, atualmente, uma das principais atividades econômicas da Amazônia. Apesar de sua baixa elasticidade, estima-se que a área impactada pela atividade extrativista madeireira é muito maior que a área desmatada propriamente. Isso ocorre por dois fatores: primeiro, porque é mais difícil identificar os desmatamentos ilegais com intervenções esparsas; segundo, porque a extração das maiores espécies implica em constante necessidade de migração dessas atividades para áreas cada vez mais internas do bioma. Isto causa uma redução na disseminação de sementes das grandes árvores, promovendo uma queda substancial da capacidade de regeneração florestal.

A maior elasticidade é encontrada na relação com as áreas protegidas. Um aumento de $10 \%$ na área das Unidades de Conservação e/ou das Terras Indígenas representa uma redução de $8,48 \%$ nas taxas anuais de desmatamento na Amazônia. Ou seja, um incremento de 1,34 mil $\mathrm{Km}^{2}$ em área protegida implica uma redução de $65,1 \mathrm{~km}^{2}$ por ano de desmatamento. Deve-se ter cautela na interpretação dos resultados, pois estes valores representam probabilidades médias. No caso das Unidades de Conservação, por exemplo, existem diferentes graus de proteção dependendo da classe e da categoria de manejo. Além disso, há grande diferença na capacidade de gestão dessas áreas (Gazoni \&
Mota, 2010b). Algumas possuem diversas infra-estruturas instaladas, como guaritas, portaria, sede administrativa, cercamento, vigilância, trilhas sinalizadas, centro de visitantes, entre outras, além de equipamentos como computadores e veículos (automóveis e barcos). Outras só existem efetivamente no papel, sendo sua proteção garantida apenas pela legislação e pela fiscalização ocasional.

Apesar do turismo na Amazônia ainda se encontrar nos estágios iniciais de desenvolvimento, sua elasticidade $(-0,271)$ em relação ao desmatamento não é insignificante. Os resultados destacam que um crescimento de $10 \%$ na atividade turística regional sugere uma redução de 2,71\% na área anualmente desmatada na região. Entretanto, deve-se atentar que esses valores representam uma média regional. Nos casos individuais, é necessário considerar os intervalos de confiança para os estimadores lineares na previsão. Apesar dos resultados do modelo multivariado reforçarem as hipóteses desta pesquisa, a técnica não é capaz de mostrar a importância de cada fator individualmente para o desmatamento no período $2015 / 2016$. Isto ocorre devido à presença, apesar de reduzida, da multicolinearidade. Assim, optou-se por realizar a repartição das covariâncias dos vetores explicativos por meio da aplicação da medida de importância relativa (Pratt, 1987). A Tabela 3 apresenta os resultados das estimativas da importância de cada fator para o desmatamento no período. 
Tabela 3 - Importância do turismo para a proteção florestal regional*

\begin{tabular}{|c|c|c|c|c|c|c|c|c|c|}
\hline & \multirow[b]{2}{*}{$\beta^{*}$} & \multirow[b]{2}{*}{$\rho$} & \multirow[b]{2}{*}{ E } & \multirow[b]{2}{*}{$\delta$} & \multirow[b]{2}{*}{$\mathrm{V}(\delta)$} & \multicolumn{2}{|c|}{$\begin{array}{c}\text { Intervalo de } \\
\text { confiança de } 95 \% \\
\text { para } \delta\end{array}$} & \multirow[b]{2}{*}{$D_{i}$} & \multirow[b]{2}{*}{$D_{i} \%$} \\
\hline & & & & & & INF & SUP & & \\
\hline Pecuária & 0,318 & 0,335 & 0,302 & 0,106 & 0,120 & 0,061 & 0,151 & 1491,2 & $19,5 \%$ \\
\hline Agricultura & 0,251 & 0,308 & 0,159 & 0,077 & 0,075 & 0,042 & 0,113 & 1047,6 & $13,7 \%$ \\
\hline Ext. Madeira & 0,237 & 0,267 & 0,151 & 0,063 & 0,067 & 0,030 & 0,097 & 749,4 & $9,8 \%$ \\
\hline Assentamentos & 0,283 & 0,271 & 0,246 & 0,077 & 0,095 & 0,037 & 0,117 & 856,5 & $11,2 \%$ \\
\hline Áreas Protegidas & $-0,309$ & $-0,337$ & $-0,848$ & 0,104 & 0,113 & 0,061 & 0,148 & 1361,2 & $-17,8 \%$ \\
\hline Turismo & $-0,242$ & $-0,183$ & $-0,271$ & 0,039 & 0,070 & 0,010 & 0,056 & $-282,9$ & $-3,7 \%$ \\
\hline Maranhão ${ }^{1}$ & 0,387 & 0,355 & 0,145 & 0,137 & 0,177 & 0,083 & 0,192 & 1429,9 & $18,7 \%$ \\
\hline Pará1 & 0,275 & 0,262 & 0,054 & 0,072 & 0,090 & 0,033 & 0,111 & 917,6 & $12,0 \%$ \\
\hline Outros ${ }^{2}$ & - & - & - & - & - & - & - & 1147,1 & $15,1 \%$ \\
\hline
\end{tabular}

As maiores importâncias relativas $(\delta)$ são da localização no Maranhão $(0,137)$, da pecuária $(0,106)$ e das áreas protegidas $(0,104)$; por outro lado, os aspectos significativos, mas menos importantes neste período são a extração de madeira $(0,063)$ e o turismo $(0,039)$. Esses resultados permitem estimar a participação percentual de cada variável explicativa no comportamento da variável explicada. Os resultados destacam que, de agosto de 2015 a julho de 2016, a pecuária bovina foi responsável por $19,5 \%$ do desmatamento no bioma Amazônia. Isto representa a perda de uma área florestal de 1.491,2 km². A agricultura, em forte expansão no período, contribuiu com $13,7 \%$ do desmatamento, ou seja, 1.047,6 km². A madeira foi responsável pela supressão de $749,4 \mathrm{~km}^{2}$ de área florestal, 9,8\% do desmatamento ocorrido. Os assentamentos rurais são outro importante vetor de desmatamento na Amazônia. No período analisado eles foram responsáveis por
$11,2 \%$ de todo o desmatamento regional: foram mais $856,5 \mathrm{~km}^{2}$ perdidos. Além desses aspectos político-econômicos, a localização espacial nos estados do Pará e do Maranhão apresenta grande importância para a previsão das taxas de desmatamento. Estima-se que $18,7 \%$ de todo o desmatamento regional esteja relacionado com algum aspecto inerente ao estado do Maranhão. Isto significa $1.429,9 \mathrm{~km}^{2}$ desmatados em 2015/2016. Assim como no Maranhão, o estado do Pará apresenta características que o indicam responsável por $12,0 \%$ do desmatamento anual, ou seja, $917,6 \mathrm{~km}^{2}$ destruídos. Outros fatores explicativos não incluídos no modelo representam $15,1 \%$ do desmatamento regional, uma área de $1.147,1 \mathrm{~km}^{2}$.

Apesar de muitas serem as forças promotoras do desmatamento regional, outros aspectos político-econômicos apresentam-se como forças protetoras da cobertura do solo, repelindo parte das pressões advindas dos 
vetores explicativos, reduzindo seu impacto. Este estudo identificou duas variáveis inversamente correlacionadas ao desmatamento regional: as áreas protegidas e o turismo. $\mathrm{A}$ criação de áreas protegidas é, com certeza, a principal estratégia de proteção ambiental na Amazônia. Utilizada com vigor na região do arco do desflorestamento, tem dificultado o avanço da fronteira agropecuária para áreas mais internas do bioma. As principais correlações das áreas protegidas são com a extração de madeira e com a pecuária bovina o que sugere uma atuação mais eficaz na proteção contra a pressão exercida por esses importantes agentes do desmatamento. Não foram encontradas correlações entre as áreas protegidas com a agricultura e com os assentamentos rurais e pela agricultura. Isso ocorreu, talvez, por sua heterogeneidade característica na Amazônia.

O turismo apesar de ter correlação significante com as taxas de desmatamento anual, após a extração de outros fatores a ele correlacionados no espaço, mostrou-se com uma pequena influência relativa no desmatamento, apesar de significativa. Os resultados sugerem que se não existisse turismo na Amazônia as taxas de desmatamento no período 2015/2016 teriam sido 3,7\% maiores, ou seja, o turismo foi responsável por evitar o desmatamento de $282,9 \mathrm{~km}^{2}$ de florestas somente neste período. São muitas as formas pelas quais o turismo pode influenciar o ritmo do desmatamento regional. Considerando suas correlações no espaço, a proteção gerada pelo turismo pode apresentar maior eficiência frente às pressões causadas pela pecuária e pela agricultura. De outra forma, sua baixa correlação com a extração de ma- deira sugere que, diferente das áreas protegidas, o turismo tem pouca influência sobre as pressões geradas pela exploração da madeira.

Os modos pelos quais o turismo influência inversamente as taxas de desmatamento em nível regional devem ser objeto de futuras investigações. Todavia, podem-se sugerir algumas hipóteses sobre esse aspecto. Primeiro, em nível macroeconômico, a inserção do turismo na economia regional reduz a dependência de outras atividades econômicas, muitas vezes monopolísticas em determinadas sub-regiões do bioma. Além de reduzir a pressão sobre as florestas por meio da substituição das atividades produtivas com maiores capacidades degradadoras, o crescimento do peso do turismo na economia gera maior concorrência na alocação dos recursos financeiros, sejam públicos ou privados. Todos esses aspectos promovem a redução do impacto efetivo na cobertura florestal. Segundo, o turismo também promove uma maior valorização da qualidade dos recursos naturais. Ao mesmo tempo, problemas ambientais tornam-se cada vez mais visíveis e indesejados por visitantes, empresários e residentes, exigindo uma atuação mais rigorosa do poder público, incluindo a intensificação da fiscalização. Terceiro, além de ampliar sua importância econômica, o turismo pode financiar a conservação das áreas protegidas, reforçando sua eficiência. As taxas de ingresso e outros gastos realizados pelos visitantes nesses espaços aliadas aos recebimentos pelo uso do espaço pela iniciativa privada (hotéis, restaurantes, etc.) e por outras taxas cobradas de agências e operadoras podem ser direcionadas para o manejo de áreas prio- 
ritárias para a conservação. Por último, o turismo promove o envolvimento das populações do entorno com a atividade e, consequentemente, com a conservação.

Contudo, é preciso ter cuidado com os impactos do turismo em nível local, que podem ser graves. Não é sempre que o turismo é uma alternativa. Em muitos casos não há a conjunção dos fatores necessários para a geração de uma demanda efetiva e relativamente estável, o que torna seu desenvolvimento inviável economicamente. Em outros, as áreas próximas de grandes concentrações populacionais, com facilidade de acesso e com recursos de alta atratividade podem não ser opção, principalmente se não houver confiança nos órgãos gestores do turismo e do meio ambiente que atuam em nível local e regional, pois nesses espaços pode ocorrer crescimento descontrolado da demanda turística.

\section{CONSIDERAÇÕES FINAIS}

O turismo na Amazônia encontra-se nos primeiros estágios do processo de desenvolvimento. Apesar disso, seu desenvolvimento vem sendo apontado como uma estratégia para a sustentabilidade da Amazônia, inclusive, para redução do desmatamento regional. Neste sentido, este trabalho analisou a importância relativa do turismo para a redução do ritmo do desmatamento regional. Para isso, foram aplicadas as técnicas de regressão múltipla combinadas com a Medida de Pratt. Não é novidade que técnicas de regressão múltipla são bastante adequadas ao estudo do desmatamento, que possui vários fatores explicativos. Neste estudo, não foi diferente, apenas foi preciso aplicar a repartição das covariâncias pela Medida de Pratt para obter um estimador livre das influências da multicolinearidade.

Os resultados sugeriram que o ritmo do desmatamento regional é função de diversos fatores explicativos: a pecuária bovina (cabeças); a agricultura (área das lavouras permanentes e temporárias); a extração de madeira (tora); o tamanho dos assentamentos rurais (famílias); a extensão das áreas protegidas (Unidades de Conservação e Terras Indígenas); a localização nos estados do Pará e do Maranhão, e o desenvolvimento do turismo (leitos). Os resultados destacaram, ainda, que se não existisse turismo na Amazônia o incremento do desmatamento ocorrido em 2015/2016 teria sido maior, o que sugere a possibilidade de utilização do turismo como uma estratégia de conservação regional. Deve-se atentar, entretanto, que este é o primeiro trabalho em nível macrorregional que estuda as relações entre o turismo e o desmatamento na Amazônia. Portanto, estudos complementares devem ser realizados para a confirmação e ampliação da compreensão acerca dessas relações. Como a taxa de turismo utilizada neste estudo foi uma variável em nível estadual e não microrregional, sugere-se a busca de dados em menor dimensão (microrregional) para aproximar os estimadores. Além disso, como foi utilizada uma série de corte, diversas variáveis exógenas não puderam ser utilizadas, tais como: o câmbio, o efeito dos anos eleitorais, das taxas de juros, dos preços dos produtos agrícolas, entre outros. Por isso, sugere-se estrutu- 
rar dados em painel para melhorar a representatividade dos estimadores.

Por fim, pode-se sugerir que o turismo é uma boa estratégia de conservação regional em longo prazo. Entretanto, como seus impactos socioambientais locais podem ser indesejáveis e, muitas vezes, graves, é imperativo que as políticas de desenvolvimento do turismo incorporem as preocupações com essas externalidades, já que, na Amazônia, a sustentabilidade se tornou a própria finalidade do desenvolvimento em si.

\section{REFERÊNCIAS}

Adeney, J. M., Christensen Jr, N. L., \& Pimm, S. L. (2009). Reserves protect against deforestation fires in the Amazon. PLos One, 4(4), 5014-5026.

Albagli, S. (2001). Amazônia: fronteira geopolítica da biodiversidade. Parcerias Estratégicas, 12(6), 611.

Almeida, A. W. D., \& Marin, R. A. (2010). Campanhas de desterritorialização na Amazônia: o agronegócio e a reestruturação do mercado de terras. In: Bolle, W., \& de Castro, E. (Eds.) Amazônia, região universal e teatro do mundo. São Paulo: Globo, p. 141-159.

Almeyda, A., Broadbent E., Wyman, M. S., \& Durham, W. H. (2010). Ecotourism impacts in the Nicoya Peninsula, Costa Rica. International Journal of Tourism Research, 12(6), 803-819.

Andersen, L. E., Granger, C. W., Reis, E. J., Weinhold, D., \& Wunder, S. (2002). The dynamics of deforestation and economic growth in the Brazilian Amazon. Cambridge: Cambridge University Press.

Araújo Jr., J. T., \& Costa, K. P. (2010). Abertura comercial e inserção internacional: os casos do Brasil, China e Índia. In: Bauman, R. (Org.). O Brasil e os demais BRICs: comércio e política. Brasília: CEPAL/IPEA, 61-78.
Araujo, C. D.; Carvalho, A. G.; Silva, C. D. (2005). Turismo na llha Grande: comparando a percepção dos moradores da Vila Abraão e da Vila Dois Rios em relação ao impacto ambiental. Caderno Virtual de Turismo, 5(3), 18-26.

Baccini, A. G. S. J., Goetz, S. J., Walker, W. S., Laporte, N. T., Sun, M., Sulla-Menashe, D., \& Samanta, S. (2012). Estimated carbon dioxide emissions from tropical deforestation improved by carbon-density maps. Nature Climate Change, 2(3), 182.

Barlow, J., Lennox, G. D., Ferreira, J., Berenguer, E., Lees, A. C., Mac Nally, R., \& Parry, L. (2016). Anthropogenic disturbance in tropical forests can double biodiversity loss from deforestation. $\mathrm{Na}$ ture, 535(7610), 144.

Batistella, M., \& Moran, E. F. (2005). Dimensões humanas do uso e cobertura das terras na Amazônia: uma contribuição do LBA. Acta Amazonica, 35(2), 239-247.

Becker, B. (2004). Amazônia: geopolítica na virada do terceiro milênio. Rio de Janeiro: Garramond.

Boavida-Portugal, I., Rocha, J., \& Ferreira, C. C. (2016). Exploring the impacts of future tourism development on land use/cover changes. Applied Geography, 77, 82-91.

Brandão, C. N.; Barbieri, J. C.; Reyes Junior, E. (2015) Análise da sustentabilidade do turismo: um estudo em comunidades indígenas no Estado de Roraima, Brasil. Revista Brasileira de Pesquisa em Turismo, 9(2), 500-518.

Brasil. Ministério do Meio Ambiente. (2009). Florestas do Brasil em resumo. Dados de 2005-2009. Brasília: MMA/SBF.

Brasil. Ministério do Turismo. (2015). Anuário Estatístico do Turismo: ano base 2014. Vol 42. Brasília: MTUR/SNPT.

Buckley, R. (2011). Tourism and environment. Annual Review of Environmental Resources, 36, 397416.

Calandino, D., Wehrmann, M., \& Koblitz, R. (2012). Contribuição dos assentamentos rurais no desmatamento da Amazônia: um olhar sobre o Estado do 
Pará. Desenvolvimento e Meio Ambiente, 26, 161170.

Caldas, M., Walker, R., Arima, E., Perz, S., Aldrich, S., \& Simmons, C. (2007). Theorizing land cover and land use change: the peasant economy of Amazonian deforestation. Annals of the Association of American Geographers, 97(1), 86-110.

Cattaneo, A. (2005). Inter-regional innovation in Brazilian agriculture and deforestation in the Amazon: income and environment in the balance. Environment and Development Economics, 10, 485-511.

Caviglia-Harris, J. L., Sills, E. O., \& Mullan, K. (2013). Migration and mobility on the Amazon frontier. Population and Environment, 34(3), 338-369.

Chen, B.; Nakama, Y.; Zhang, Y. (2017) Traditional village forest landscapes: tourists attitudes and preferences for conservation. Tourism Management, 59, 652-662.

Corona, R., Galicia, L., Palacio-Prieto, J. L., Bürgi, M., \& Hersperger, A. (2016). Local deforestation patterns and driving forces in a tropical dry forest in two municipalities of southern Oaxaca, Mexico (1985-2006). Investigaciones Geográficas, Boletín del Instituto de Geografía, 2016(91), 86-104.

Delazeri, L. M. (2016). Determinantes do Desmatamento nos Municípios do Arco Verde-Amazônia Legal: uma abordagem econométrica. Revista Economia Ensaios, 30(2), 11-34.

Doan, T. M. (2013). Sustainable ecotourism in Amazonia: evaluation of six sites in southeastern Peru. International Journal of Tourism Research, 15(3), 261-271.

Ferreira, M. D. P., \& Coelho, A. B. (2015). Desmatamento recente nos estados da Amazônia Legal: uma análise da contribuição dos preços agrícolas e das políticas governamentais. Revista de Economia $e$ Sociologia Rural, 53(1), 91-108.

Food and Agriculture Organization of the United Nations (2016). State of the World's forests 2016: forests ang agriculture - land use challenges and opportunities. Roma: FAO.
Fox, D. M., Witz, E., Blanc, V., Soulié, C., PenalverNavarro, M., \& Dervieux, A. (2012). A case study of land cover change (1950-2003) and runoff in a Mediterranean catchment. Applied Geography, 32, 810821.

Galton, F. (1886). Family likeness in stature. Proceedings of the Royal Society, 40, 42-72.

Gaughan, A. E., Binford, M. W., \& Southworth, J. (2009). Tourism, forest conversion, and land transformations in the Angkor basin, Cambodia. Applied Geography, 29(2), 212-223.

Gazoni, J. L. (2014). Amazônia: ambiente, desenvolvimento e sustentabilidade. Rio de Janeiro: NEA.

Gazoni, J. L. (2018) A visitação pública e o desmatamento nas Unidades de Conservação da Amazônia: uma abordagem econométrica. In: Colóquio Cenários, Ciência e Desenvolvimento Turístico, Anais... Gramado, 12 a 14 de abril de 2018, p. 35-52.

Gazoni, J. L., \& Mota, J. A. (2010a). O Sistema Nacional de Unidades de Conservação da Natureza: realidade e perspectivas. In: Alvarez, A. R., \& Mota, J. A. (Ed.). Sustentabilidade Ambiental no Brasil: biodiversidade, economia e bem-estar humano. v.7, Brasília: Instituto de Pesquisa Econômica Aplicada, p. 359-384.

Gazoni, J. L., \& Mota, J. A. (2010b). Fatores políticoeconômicos do desmatamento na Amazônia Oriental. Sustentabilidade em Debate, 1(1), 25-42.

Green, P. E., Carroll, J. D., \& Desarbo, W. S. (1978). A new measure of predictor variable importance in multiple regression. Journal of Marketing Research, 15, 356-360.

Gujarati, D. (2006). Econometria básica. Rio de Janeiro: Elsevier.

Hahn, M. B., Gangnon, R. E., Barcellos, C., Asner, G. P., \& Patz, J. A. (2014). Influence of deforestation, logging, and fire on malaria in the Brazilian Amazon. PLoS One, 9(1), 85711-85725.

Hoang, H. T. T., Vanacker, V., Van Rompaey, A., Vu, K. C., \& Nguyen, A. T. (2014). Changing human- 
landscape interactions after development of tourism in the northern Vietnamese Highlands. Anthropocene, 5, 42-51.

Hoefle, S. W. (2016). Multi-functionality, juxtaposition and conflict in the Central Amazon: Will tourism contribute to rural livelihoods and save the rainforest? Journal of Rural Studies, 44, 24-36.

Instituto Brasileiro de Geografia e Estatística (2005). Biomas do Brasil. Disponível em: http://mapas.mma.gov.br/i3geo/datadownload.htm. Acesso em 12/07/2017.

Instituto Chico Mendes de Conservação da Biodiversidade (2011). Roteiro metodológico para manejo de impactos da visitação: com enfoque na experiência do visitante e na proteção dos recursos naturais e culturais. Brasília: ICMBIO.

Intergovernmental Panel on Climate Change (2014). Climate Change 2014: Synthesis Report. Contribution of Working Groups I, II and III to the Fifth Assessment Report of the Intergovernmental Panel on Climate Change. Geneva, IPCC.

Kuvan, Y. (2005). The use of forests for the purpose of tourism: the case of Belek Tourism Center in Turkey. Journal of Environmental Management, 75(3), 263-274.

Kuvan, Y., \& Akan, P. (2005). Residents' attitudes toward general and forest-related impacts of tourism: the case of Belek, Antalya. Tourism Management, 26(5), 691-706.

Laurance, W. F., Albernaz, A. K., Schroth, G., Fearnside, P. M., Bergen, S., Venticinque, E. M., \& Costa, C. (2002). Predictors of deforestation in the Brazilian Amazon. Journal of Biogeography, 29(5-6), 737748.

Lawrence, D., \& Vandecar, K. (2015). Effects of tropical deforestation on climate and agriculture. $\mathrm{Na}$ ture Climate Change, 5(1), 27.

Lewis, S. L., Brando, P. M., Phillips, O. L., van der Heijden, G. M., \& Nepstad, D. (2011). The 2010 amazon drought. Science, 331(6017), 554-554.
Linhares Jr., J. (2014). No MA, PF prende servidores suspeitos de praticar crimes no Ibama. Folha de São Paulo, 02 de dezembro de 2014. Disponível em: http://www1.folha.uol.com.br der/2014/12/1556544-no-ma-pf-prende-servidores-suspeitos-de-praticar-crimes-no-ibama. shtml. Acesso em 04 de janeiro de 2018.

Liu, J., Qu, H., Huang, D., Chen, G., Yue, X., Zhao, X., $\&$ Liang, Z. (2014). The role of social capital in encouraging residents pro-environmental behaviors in community-based ecotourism. Tourism Management, 41, 190-201.

Lobo, H. A. S.; Moretti, E. C. (2009). A natureza das políticas públicas: ecoturismo e conservação ambiental em Bonito - MS. Observatório de Inovação do Turismo, 4(1), 1-15.

Luíse, D. (2011). Corrupção é algo crônico em Secretarias de Meio Ambiente na Amazônia, diz ex-secretário. Carta Capital, 17 de março de 2011. Disponível em: https://www.cartacapital.com.br/sustentabilidade/corrupcao-e-algo-cronico-em-secre tariasde-meio-ambiente-na-amaz onia-diz-ex-secretario. Acesso em 04/12/2018.

Mao, X., Meng, J., \& Wang, Q. (2014). Tourism and land transformation: a case study of the Li River Basin, Guilin, China, Journal of Mountain Science, 11(6), 1606-1619.

Margulis, S. (2003). Causas do desmatamento da Amazônia Brasileira. Brasília: Banco Mundial.

Medvigy, D., Walko, R. L., \& Avissar, R. (2011). Effects of deforestation on spatiotemporal distributions of precipitation in South America. Journal of Climate, 24(8), 2147-2163.

Navarrete, A. A., Tsai, S. M., Mendes, L. W., Faust, K., Hollander, M., Cassman, N. A., \& Kuramae, E. E. (2015). Soil microbiome responses to the shortterm effects of Amazonian deforestation. Molecular Ecology, 24(10), 2433-2448.

Nepstad, D. C., Verssimo, A., Alencar, A., Nobre, C., Lima, E., Lefebvre, P., \& Cochrane, M. (1999). Largescale impoverishment of Amazonian forests by logging and fire. Nature, 398(6727), 505-508. 
Nepstad, D., Schwartzman, S., Bamberger, B., Santilli, M., Ray, D., Schlesinger, P., \& Rolla, A. (2006). Inhibition of Amazon deforestation and fire by parks and indigenous lands. Conservation Biology, 20(1), 65-73.

Nyaupane, G. P., \& Poudel, S. (2011) Linkages among biodiversity, livelihood, and tourism. Annals of Tourism Research, 38(4), 1344-1366.

Oliveira, F. T., Silva, I. C., Matos, J. F. R., \& Hara, F. A. S. (2010). Ecoturismo no Rio Puraquequara: suporte para inclusão social e proteção ambiental. Sociedade \& Natureza, 22(2), 283-295.

Oosterzee, P. (2000). Ecotourism and biodiversity conservation: two-way track. Pacific Conservation Biology, 6(2), 89-93.

Peralta, N. (2012). Ecoturismo de base comunitária na Amazônia: uma análise comparativa. Observatório de Inovação do Turismo, 7(1), 1-16.

Pfaff, A. S. P. (1999). What drives deforestation in the Brazilian Amazon? Evidence from satellite and socioeconomic data. Journal of Environmental Economics and Management, 37, 26-43.

Pindyck. R. S., \& Rubinfeld, D. L. (2004). Econometria: modelos e previsões. Rio de Janeiro: Elsevier.

Pratt, J. W. (1987). Dividing the indivisible: using simple symmetry to partition variance explained. In: Pukkila, T., \& Puntanen, S. (Eds.). Proceedings of the Second International Conference in Statistics. Tampere, Finland: University of Tampere, 245-260.

Reis, E. J., \& Margulis, S. (1991). Perspectivas econômicas do desflorestamento da Amazônia. Texto para Discussão (Ipea), v. 215. Brasília: Instituto de Pesquisa Econômica Aplicada.

Robalino, J., Pfaff, A., \& Villalobos, L. (2015). Deforestation spillovers from Costa Rican Protected Areas. Latin American and Caribean Environmental Economics Program Working Paper Series, 78, 1-24.

Skole, D. L., Chomentowski, W. H., Salas, W. A., \& Nobre, A. D. (1994). Physical and human dimensions of deforestation in Amazonia. BioScience, 44(5), 314-322.
Spracklen, D. V., \& Garcia-Carreras, L. (2015). The impact of Amazonian deforestation on Amazon basin rainfall. Geophysical Research Letters, 42(21), 9546-9552.

Stevens, S. (2003). Tourism and deforestation in the Mt Everest region of Nepal. Geographical Journal, 169(3), 255-277.

Stronza, A., \& Pegas, F. (2008). Ecotourism and conservation: two cases from Brazil and Peru. Human Dimensions of Wildlife, 13(4), 263-279.

Suntikul, W., \& Dorji, U. (2015). Tourism development: the challenges of achieving sustainable livelihoods in Bhutan's remote reaches. International Journal of Tourism Research, 18(5), 447-457.

Thomas, R. D., Zhu, P. C., \& Decady, Y. J. (2007). Point estimates and confidence intervals for variable importance in multiple linear regression. Journal of Educational and Behavioral Statistics, 32, 6191.

Uhl, C., \& Vieira, I. C. G. (1989). Ecological impacts of selective logging in the Brazilian Amazon: a case study from the Paragominas region of the State of Para. Biotropica, 21, 98-106.

United Nations Environment Programme (2005). Forging links between protected areas and the tourism sector: how tourism can benefit conservation. Paris: UNEP.

Solinge, T. B. (2010). Deforestation crimes and conflicts in the Amazon. Critical Criminology, 18(4), 263-277.

Vijay, R., Kushwaha, V. K., Chaudhury, A. S., Naik, K., Gupta, I., Kumar, R., \& Wate, S. R. (2016). Assessment of tourism impact on land use/land cover and natural slope in Manali, India: a geospatial analysis. Environmental Earth Sciences, 75(1), 20-28.

Walker, R., Perz, S., Caldas, M., \& Silva, L. G. T. (2002). Land use and land cover change in forest frontiers: The role of household life cycles. International Regional Science Review, 25(2), 169-199.

Woodridge, J. M. (2010). Introdução à Econometria: uma abordagem moderna. São Paulo: Cengage Learning. 
World Tourism Organization (2002). World Ecotourism Summit: final report. Madrid, UNWTO.

World Tourism Organization (2013). Sustainable tourism for development: enhancing capacities for sustainable tourism for development in developing countries. Madrid, UNWTO.

World Wildlife Fund for Nature (2003). Manual de ecoturismo de base comunitária: ferramentas para um planejamento responsável. Brasília: WWF-Brasil.

World Wildlife Fund for Nature (2013). Amazon Species Report 2010-2013. Disponível em: http://wwf.panda.org/what we do/where we w ork/amazon/species/amazon s pecies report 2010 2013.htm. Acesso em 12/12/2017.

Young, C. E. F. (1998). Public policies and deforestation in the Brazilian Amazon. Planejamento e Políticas Públicas, 18, 201-223.

Zhao, J., Li, Y., Wang, D., \& Xu, D. (2011). Tourisminduced deforestation outside Changbai Mountain
Biosphere Reserve, northeast China. Annals of Forest Science, 68(5), 935-941.

Zhong, L., Deng, J., \& Xiang, B. (2008). Tourism development and the tourism area life-cycle model: a case study of Zhangjiajie National Forest Park, China. Tourism Management, 29(5), 841-856.

Informações dos autores

\section{Jefferson Lorencini Gazoni}

Turismólogo. Doutor em Desenvolvimento Sustentável pela Universidade de Brasília (UnB).

E-mail: jlgazoni@unb.br.

ORCID: 0000-0002-6480-0897.

\section{Iara Lucia Gomes Brasileiro}

Bióloga. Doutora em Ciências pela Universidade de São Paulo (USP). Professora Associada do Centro de Excelência em Turismo da Universidade de Brasília (UnB).

E-mail:ibrasileiro@unb.br ORCID: 0000-0002-3969-6506. 